\title{
Expert's Comment concerning Grand Rounds Case entitled "Percutaneous cement discoplasty for the treatment of advanced degenerative disk disease in elderly patients"
}

\author{
(C. Sola, et al., Eur Spine J; 2018: DOI 10.1007/s00586-018-5547-7)
}

Aron Lazary ${ }^{1}$

Received: 26 July 2020 / Accepted: 7 August 2020 / Published online: 19 August 2020

(C) The Author(s) 2020

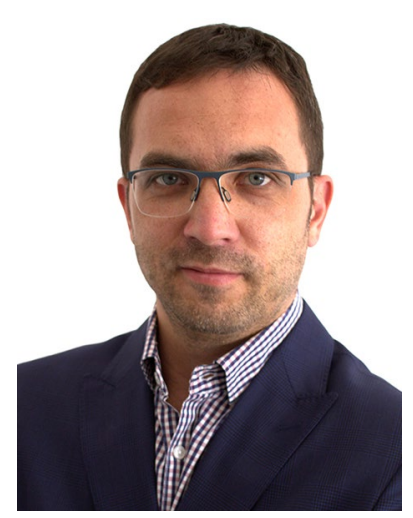

Sola et al.'s paper is a well-written case report and a clear summary about the technical details of the minimally invasive, percutaneous cement discoplasty (PCD). As a member of the team that originally developed the PCD technique leaded by Peter Pal Varga, I am very happy to see the growing body of evidence supporting the method to help more and more suffering patients. Publication of clinical and basic scientific evidence is crucial in relation to any medical method especially in case of a new treatment possibilitythis is the responsibility of the original developers as well as the surgeons who introduce the technique into their practice. Since our first report [1] and detailed technical description [2], a subsequent paper about the effect of PCD on spinal alignment and indirect foraminal decompression has been published by our team [3] and just recently, the results of the

Aron Lazary

aron.lazary@bhc.hu

1 National Center for Spinal Disorders, Department of Spine Surgery, Semmelweis University, Kiralyhago u. 1-3, Budapest 1125, Hungary first in vitro biomechanical study about PCD was submitted for publication [4]. An independent case series has been also published by Willhuber et al. [5], and the topic has induced a real debate in the spine community [6-8].

In case of a surgical technique, the safety and effectiveness issues are strongly related to the proper indication and the accurate implementation. One of the strengths of Sola's paper is that they clearly describe the clinical and radiological indication for PCD (long term, significant mechanical low back pain without neurology, resistant to conservative treatment and a significant vacuum sign in the disk space). In our experience, the careful investigation of this latest feature is one of the key elements of the good clinical outcome. Only spinal levels with significant vacuum phenomenon (pneumodisk in Sola's words) can be treated with PCD technique. In case of a small vacuum sign, when more than half of the disk space is filled with degenerated disk tissue, the risk of early and late complications is high. The aim of the PCD is to stabilize the segment ceasing the vertical instability related to the advanced disk degeneration. We agree with Sola; the presence of vertical instability (he calls it accordion phenomenon i.e., a significant disk height variation between the standing and supine position in the presence of vacuum phenomenon) is the adequate radiological sign for the unstable segment and for the indication of PCD. One other important radiological feature in spinal levels suitable for PCD is the sclerosis of the vertebral endplates which provide solid contact surfaces for the PMMA spacer.

Sole et al. give a proper description of the surgical technique with some considerable modification of the originally published one. They emphasized the importance of the proper positioning to improve the sagittal and coronal lumbar alignment, and we strongly agree with this point. The alignment correction what can be achieved with the positioning and can be stabilized with the PCD is one of the factors 
of good clinical outcome [3]. In our practice, the L5-S1 level is also treated via extra-pedicular access, but individually, the described transpedicular approach can be considered. I would argue about the need of intraoperative neurophysiological monitoring. There can be some country- and hospital-specific regulations, but from the anatomical point of view, we do not consider the use of neuromonitor necessary. It makes the procedure more expensive and longer while the risk of nerve root injury is minimal if the surgeon keeps the rules when the disk is approached with the Jamshidi needle and if the fluoroscopy guidance is adequate during the cement injection. The description of the neuro-monitoring is very clear, but it would be important to know that how often did they notice abnormal potentials and clinically significant EMG signs in their practice. As in many clinical questions, an RCT could clarify properly this issue, however, in our case series, none of the patients suffered from nerve root injury after PCD procedure. To avoid the cement leakage in our about seven-year experience with PCD, the tip of the cannula is introduced into the medial-anterior part of the vacuum disk space before starting the cement injection. When the space is filled with cement, the cannula has to be pulled back until the anterior border of the posterior annulus, and a small amount of cement is injected into the channel to complete the filling process.

We strongly agree with the rationale for treatment as it was described by Sola et al. and with the need of further clinical and basic science studies. In the present phase, PCD is a minimally invasive salvage treatment option for well-selected elderly patients where open stabilization surgeries are contraindicated. We found the same as Sola published that most patients benefit from a sustained clinical and radiological improvement after PCD $[1,3]$. On the other hand, a number of criticisms can be raised in relation with the technique. One of them (however, it is not the aim of the surgery) is the lack of bony fusion which can predispose for long-term mechanical complications. This issue should be studied too in the future, because so far we have no long-term data analyzed in terms of the fusion process, but from other MIS procedures (MIS fracture stabilization, oblique lumbar interbody fusion, etc.) we experienced that stabilized spinal segments can be spontaneously fused-especially in the region of facet joints and at the edges of the vertebral bodies. This process can also occur in PCD patients which can be the biomechanical explanation of the long-term favorable effect of the method. It should be considered that PCD is a method of choice in the symptomatic aging spine patients, where the main pathology is the vertical instability and consequent foraminal stenosis with nerve root irritation. The main goal and result of PCD is the enlargement of the dimensions of the intervertebral foramen by restoration and maintenance of the disk height by the injected cement.

Funding Open access funding provided by Semmelweis University.

\section{Compliance with ethical standards}

Conflict of interest None of the authors has any potential conflict of interest.

Open Access This article is licensed under a Creative Commons Attribution 4.0 International License, which permits use, sharing, adaptation, distribution and reproduction in any medium or format, as long as you give appropriate credit to the original author(s) and the source, provide a link to the Creative Commons licence, and indicate if changes were made. The images or other third party material in this article are included in the article's Creative Commons licence, unless indicated otherwise in a credit line to the material. If material is not included in the article's Creative Commons licence and your intended use is not permitted by statutory regulation or exceeds the permitted use, you will need to obtain permission directly from the copyright holder. To view a copy of this licence, visit http://creativecommons.org/licenses/by/4.0/.

\section{References}

1. Varga PP, Jakab G, Bors IB, Lazary A, Szövérfi Z (2015) Experiences with PMMA cement as a stand-alone intervertebral spacer: percutaneous cement discoplasty in the case of vacuum phenomenon within lumbar intervertebral discs. Orthopade 44(Suppl 1):S1-S7. https://doi.org/10.1007/s00132-014-3060-1

2. Varga PP, Jakab G, Szöverfi Z, Bors I, Lazary A (2018) Percutaneous cement discoplasty-minimal invasive treatment of severe disc degeneration in elderly. In: Lewandrowski KU, Schubert M, Léon JFR, Fessler RG (eds) Minimally invasive spinal surgery, 1st edn. Medical Publisher, Tokyo

3. Kiss L, Varga PP, Szoverfi Z, Jakab G, Eltes PE, Lazary A (2019) Indirect foraminal decompression and improvement in the lumbar alignment after percutaneous cement discoplasty. Eur Spine J 28:1441-1447. https://doi.org/10.1007/s00586-019-05966-7

4. Techens C, Palanca M, Eltes PE, Lazary A, Cristofolini L (2020) Testing the impact of discoplasty on the biomechanics of the intervertebral disc with simulated degeneration: an in vitro porcine study. Med Eng Phys 84:54-59

5. Willhuber GC, Kido G, Duarte MP, Estefan M, Bendersky M, Bassani J, Petracchi M, Gruenberg M, Sola C (2020) Percutaneous cement discoplasty for the treatment of advanced degenerative disc conditions: a case series analysis. Glob Spine J 10:729-734. https://doi.org/10.1177/2192568219873885

6. Xie T, Yang X, Song Y (2020) Letter to the Editor concerning "Indirect foraminal decompression and improvement in the lumbar alignment after percutaneous cement discoplasty" by Laszlo Kiss et al. (Eur Spine J; 28(6):1441-1447). Eur Spine J 29:199. https://doi.org/10.1007/s00586-019-06163-2

7. Wang H, Wang Z (2019) Letter to the Editor concerning "Indirect foraminal decompression and improvement in the lumbar alignment after percutaneous cement discoplasty" by Laszlo Kiss et al. (Eur Spine J; 28(6):1441-1447). Eur Spine J 28:3092. https://doi. org/10.1007/s00586-019-06150-7

8. Wang B, Shan L, Hao D (2018) Letter to the Editor concerning "Percutaneous cement discoplasty for the treatment of advanced degenerative disk disease in elderly patients" by Sola C, Camino Willhuber G, Kido G et al. Eur Spine J (2018): DOI 10.1007/ s00586-018-5547-7. Eur Spine J 27:1665-1666. https://doi. org/10.1007/s00586-018-5642-9

Publisher's Note Springer Nature remains neutral with regard to jurisdictional claims in published maps and institutional affiliations. 